\title{
NOTA INTRODUCTORIA
}

El Programa de Derecho de la Institución Universitaria Politécnico Grancolombiano, presenta las memorias del Seminario "Nuevos Desafíos del Derecho Privado", evento académico llevado a cabo en el campus universitario de Bogotá el 30 de octubre de 2019.

En concordancia con los estudios adelantados a través de la línea de investigación "Derecho de la Responsabilidad Civil", adscrita a las actividades investigativas del Programa, se organizó el evento que contó con la presencia de connotados juristas investigadores pertenecientes a distintas universidades de Colombia y Francia, quienes se reunieron para debatir en torno a temas controversiales que se encuentran actualmente en desarrollo en el área del Derecho Privado.

Cada época de la historia ha aportado elementos para la construcción del Derecho. En efecto, los fundamentos de esta ciencia (o disciplina) vienen desde la Antigua Grecia y Roma, de la influencia recibida por el cristianismo, de la codificación y de otros tantos movimientos, filosofías y acontecimientos que permitieron que la vida pasada de las instituciones alimentara sus caracteres actuales.

Las instituciones que a lo largo de la historia se han construido en el marco del Derecho Privado, han adquirido un significado vinculado con las transformaciones sociales. Precisamente esas confrontaciones y evoluciones testimonian los grandes cambios frente a los que el Derecho ha sido llamado a formular sus aportes.

Bajo esta perspectiva, el objetivo del Seminario estuvo enfocado en revisar una serie de fenómenos que desde el panorama de las nociones clásicas del Derecho Privado deben ser reconsideradas. Mirando hacia el futuro, trazando las evoluciones en curso y, en ciertos casos, sugiriendo vías para el cambio; los expositores aquí reunidos mostraron sus visiones para ello.

Mónica Lucía Fernández-Muñoz

Docente-investigadora

Programa de Derecho Institución Universitaria Politécnico Grancolombiano 